\title{
China's College English Translation Teaching: Importance, Problems and Suggestions
}

\author{
Qin Yao ${ }^{1,2}$ \\ ${ }^{1}$ Foreign Language and Literature Mobile Station \\ Fudan University \\ Shanghai, China \\ ${ }^{2}$ Foreign Language and Literature Department \\ Jiangsu University \\ Jiangsu, China
}

\begin{abstract}
This paper explores the problems in the perspective of current non-English college students' translation teaching in China after pointing out its significance and the reforms it has undergone. Over the past decades of years, college English education, despite its reforms of syllabuses and curriculum requirements as well as the inclusion and expansion of translation part in the national College English Test examinations, has hardly made any spectacular progress on the fostering of non-English major students' English translating capabilities. Absence of independent translation teaching courses, high-grade textbooks, and qualified teachers exists on translation teaching in college English education. Three suggestions are proposed to solve the awkward situation. First, offer independent translation courses by adding one period of specialized translation class or making translation a selective course to equip non-English college students with more translation competence to better facilitate their future careers. Second, compile special translating course books integrally, systematically, and pertinently to stimulate students' interest and enthusiasm so as to improve their real translating competence. Third, provide qualified translation faculty through appropriate training programs or recruiting specialized translation teachers. This paper pioneers a new way to the research of non-English college translation education and provides some profound insights.
\end{abstract}

Keywords—non-English college students; translation teaching; importance; problems, suggestions

\section{INTRODUCTION}

With the advent of economic globalization worldwide and China stepping into the global village, China is thirsty for translation talents and there exist huge demands for those who can proficiently translate and interpret bilingually and biculturally where exchanges of economy, trade and culture are concerned. Hence, translation teaching in China's colleges and universities is obtaining unprecedented attention. In China, English education at college level falls into two categories: the one for English majors and the other for non-English majors. Compared with the slim number of English majors who receive regular translation instructions, from whom translators or interpreters are far from adequate to meet the demands of the present market in China, the vast number of non-English majors has been generally ignored the cultivating of translation capacities, who, in the future global economic transactions, are to assume the predominant roles.

In view of this awkward situation, the present study into problems in this respect and attempts to provide solutions.

\section{THE GROWING IMPORTANCE}

"Translation has brought and continues to bring people of different culture and linguistics backgrounds closer together, it has enabled them to share a more harmonious view of the world, and it has built bridges of understanding and appreciation among different societies."[1]

Currently, with foreign exchanges booming in economic, cultural, political and other areas of communication yet little qualified translators in store, it has dawned to the higher education authorities that emphases should be laid on the urgent necessity to foster the majority of college students, namely the non-English majors, to develop comprehensive communicative abilities, especially the translating capabilities.

In a long period after the founding of P.R. China, college English translation teaching was characterized as without unified regular teaching content until the official Teaching Syllabus was pronounced.

College English Teaching Syllabus (Draft) 1980, the first launched official syllabus in China's history of College English teaching, laid heavy emphases on students' reading abilities while treating translation teaching as selective.

Syllabuses 1985/1986, claiming “to cultivate students' strong ability to read, normal ability to listen and translate and preliminary ability to write and speak”, upgraded the status of translation teaching a little bit.

Syllabus 1999 (revised edition), orientating “to develop students' great ability to read and certain abilities to listen, speak, write and translate, so that they are able to exchange information in English”, divided all language skills (listening, speaking, reading, and writing) into two general tiers, with reading in the first and listening, writing, speaking and translation in the second, which, although still giving priority to reading teaching, also gave translation teaching certain importance.

This paper is sponsored by General Financial Grant from the China Postdoctoral Science Foundation, NO. 2016M601481. 
"The early period of 21st century has witnessed a new round of overall innovations or reforms in College English teaching in China.”[2]

College English Curriculum Requirements 2004, which advocated Whole Language Approach and commanded integration of five paralleled teaching elements (speaking, writing, listening and reading and translation), further elevated the status of translation teaching.

College English Curriculum Requirements 2007 escalated translation requirements into three clearly stated levels, namely, (1) Basic requirements for translation: aided by dictionaries, students should be capable of translating essays on familiar topics from English into Chinese and vice versa with a speed of from English into Chinese being about 300 English words per hour while a speed from Chinese into English around 250 Chinese characters per hour, leading to basically accurate translations without serious mistakes in comprehension or expression. (2) Intermediate requirements for translation: assisted by dictionaries, students should be capable of translating English literature in their field on a selective basis and articles on familiar topics in popular newspapers and magazines issued in English-speaking countries with a speed of ,from English into Chinese, being about 350 English words per hour while a speed from Chinese into English around 300 Chinese characters per hour, resulting in smooth renditions conveying the original meaning without mistakes in understanding or expression on the whole through employing appropriate translation techniques. 3) Advanced Requirements for translation: aided by dictionaries, students should be capable of translating into Chinese fairly difficult English texts in literature related to their areas of specialty in newspapers and magazines published in English-speaking countries as well as Chinese introductory texts on the conditions of China or Chinese culture into English with a speed of, from English into Chinese, being about 400English words per hour while a speed, from Chinese into English, around 350 Chinese characters per hour, contributing to accuracy and smoothness and no misinterpretation, omission or mistakes in expression.

Aiming to promote the implementation of College English Teaching Syllabus and the later College English Curriculum Requirements, the National College English Testing Committee sponsored and developed a nationwide standardized biannual test called the College English Test (CET), comprising CET-4 and CET-6, which both have undergone considerable innovations since their debuts in 1987 and in 1989 respectively. The most remarkable one occurred in December, 2013, with the weight of translation part of the test increased from 5 percent to 15 percent of the total and the form of translation test shifting from sentence to a passage or paragraph translation, covering various aspects of China, including history, culture, economy, social life and the like.

From the above round of reforms and measures taken by the higher education authorities, it can be clearly seen that a growing awareness about the importance of teaching nonEnglish college students the all-round language abilities, especially translating capabilities, has been aroused among college English circle, which is due to the fact that qualified translators are in extremely short supply when China is dedicated to the economic globalization and China's enterprises are expanding markets abroad.

\section{The Pending Problems}

Over the past decades of years, college English education, despite its reforms of syllabuses and curriculum requirements as well as the inclusion and expansion of translation part in the national College English Test examinations, has hardly made any spectacular progress on the fostering of non-English major students' English translating capabilities.

As professor Luo points out, "Absence of high-grade textbooks, qualified teachers and research institutions exists on translation teaching in college English”.[3]

First, lack of independent translation teaching courses is one of the paramount problems. At present, it is a common practice for colleges and universities in China to allocate 4 classes of English a week for non-English major students, which are distributed among listening, speaking, reading and writing, exclusive of translation, which, if existing, more often than not, appears in the form of practicing important words and phrases or grammatical points in each unit in the reading courses without due attentions to cultivate students all-round translation capacities.

Second, lack of appropriate translation teaching textbooks is another leading cause. An investigation done by the author shows that the commonly adopted college English textbooks, such as New Horizon College English Integrated Course by Foreign Language Teaching and Research Press[4], and College English Intensive Reading by Shanghai Foreign Language Education Press[5] are nearly barren of the necessary translation methods and techniques, not to mention the fundamental translation concepts and theories.

Third, lack of competent college English translation teachers is one more factor. It is universally acknowledged that qualified teachers play a significant role in education. Yet currently, college English teachers possessing solid translation competence who can offer necessary translation programs are hard to find. Many elements contribute to this phenomenon, with the following two prominent. For one thing, college English teachers have neglect translation due to the fact that it is listening, speaking, reading, and writing that account for the main body of national College English Test, which is an index of their teaching abilities, where translation only occupies 15 percent of the total score and cut no figure at all. Therefore they are lack of incentives to spare enough time to dedicate to arming themselves with up-to-date translation theories and adequate practices to enhance their own translating abilities. For another, the workload of college English teachers are enormous due to the ever-increasing enrollment of universities and colleges. With an unbalanced student to teacher's ratio, they are buried in teaching and correcting students' assignments and can barely have energy to further their translation-related studies or do relevant researches.

In a word, the three mentioned situations above have impeded the cultivation of non-English major students' translation abilities. 


\section{The Feasible Suggestions}

Over the past scores of years, practical researches over teaching non-English majors translation courses have not yet appeared, but there are really some feasible suggestions to follow.

First, offer independent translation courses in college English teaching. One of the ideal solutions is to set aside a certain amount of special time for translation teaching. For example, adding one period of class by increasing the current 4 classes of English a week to 5 a week, or alternatively, 4 in the odd week, and 5 in the even week. The additional class is committed to the instructions of translation theories and the training of basic translation skills and techniques and the practice of translation materials relating to the students' majors. What's more, make translation a selective course for those who have passed the CET6 and are interested in it and willing to equip themselves with more translation competence to better facilitate their future careers.

Second, select appropriate translation teaching textbooks. The first and foremost is to compile special translating course books integrally, systematically, and pertinently, which can fully satisfy the non-English students' demands and provide guidance to their translation practice, especially those on translation skills and techniques and theories, for "fundamentally speaking, translation practices have to learn theories, or their practice is just primitive intuitive responses, their thinking is lack of purpose, and their operation is devoid of consistency, and their methods are devoid of validity”.[6]

The next step is to choose appropriate translating materials. Useful translating materials can undoubtedly stimulate students' interest and enthusiasm so as to improve their real translating competence. Newspapers and magazine both at home and abroad with diverse subjects regarding trade and commerce, science and technology, cultural and social aspects and so on provide good material sources. What's more, to prepare the students for future careers, deliberately choosing some translation materials concerning their majors, such as from politics, economics, government, business, finance and so on, is also compulsory. Some articles in their College English textbooks may also serve as good translating practice materials. In addition, Internet gives college students an easy access to abundant translation materials. Besides, some good English films and popular English songs can also serve as translating materials to stimulate students' passion for learning translation and eventually enhance their abilities of translation.
Third, provide qualified translation faculty. First of all, advanced translating courses should be set up for the CET teachers, among whom a selective amount should be encouraged to spare energy to participate in the training programs when appropriate training time, like the summer vacations which last two month or so, is scheduled. Besides, graduates from higher institutions with translation degrees should be recruited to form the CET special translation team to cover the urgent shortage of qualified CET translation teachers.

\section{CONCLUSION}

Throughout the paper, the author illustrates the wide awareness of the importance of non-English major college students' translation ability cultivation in China, explores the problems commonly existing in the present college English translation teaching and proposes solutions to address them.

With China's ever-escalating involving in global economy and the deepening of world cooperation in all respects including culture, science and technology, economy and social life, demands for qualified translators in various domains are booming, which calls for colleges and universities shouldering the corresponding responsibilities to cultivate non-English majors, who account for more than 90 percent of college students, to ensure their preparedness for the modern workplaces. First and foremost, adequate translating courses should be set aside and guaranteed; Secondly, systematic and interesting translating materials should be supplied; Last but, by no means, last, certified translation teachers should be inscribed to integrate pertinent translation theories and practical teaching methods into efficient translation teaching.

\section{REFERENCES}

[1] Mona Baker, (ed.), Encyclopedia of Translation Studies. London: Routledge, 1998, p.8.

[2] Cai Jigang, A Course in College English Translation. Shanghai: Shanghai Foreign Language Education Press, 2004, p.1. (In Chinese)

[3] Luo Xuanming, "Translation teaching in China: Problems and Prospects”, Chinese Translators Journal, 2002 (4), pp. 56-58. (In Chinese)

[4] Zheng Shutang, New Horizon College English Integrated Course, 2rd ed., book1-4.Beijing: Foreign Language Teaching and Research Press, 2011.

[5] Dong Yafen, College English Intensive Reading, 3rd ed., book1-6. Shanghai : Shanghai Foreign Language Education Press. 2011.

[6] Wang Dongfeng, "Translation studies in China: reflections at the end of the century”, Chinese Translators Journal, 1999 (1), pp. 7-11. (In Chinese) 